\title{
Special issue on Toxicology of Pesticides
}

\section{Francisco Sánchez-Bayo ${ }^{1 *}$ and Richard Ortega ${ }^{2 * *}$}

${ }^{1}$ Centre for Ecotoxicology, University of Technology Sydney, Lidcombe NSW 2141, Australia

${ }^{2}$ University of Bordeaux, CENBG, UMR 5797, F-33170 Gradignan, France

Since the mid-1960s, environmental toxicology focussed on the effects of bioaccumulation of organochlorine insecticides in organisms, and their consequences for populations of species in the wild. Prompted by the release of Silent Spring [1], scientists sifted focus to the ecological effects of pesticides, thus expanding the narrow field of pesticide toxicology that had been restricted to its effects on pests, weeds and pathogenic fungi since its beginnings. The ensuing decades will witness a tremendous gathering of data related to the toxic impacts that insecticides, herbicides and fungicides have on organisms and ecosystems [2].

Despite these efforts, our understanding of the mechanisms of toxicity at different levels of biological organisation has not kept abreast with the overwhelming progress experienced in the development of new pesticides. While chemical companies introduced new plant protection products in the market at a staggering pace, environmental toxicology has trailed behind. Part of the reason is that the impacts of those new chemicals in the environment are not apparent immediately after their release, but usually it takes years for the negative consequences of their activity to be noticed. Let's not forget that it took 25 years from the introduction of DDT in agriculture until the decline in population of raptors was observed [3], and another 10 years to prove that this and other organochlorine insecticides were responsible for such declines [4].

Chemical companies have moved away from producing substances that accumulate in the body of organisms (typically lipophilic substances), and are now developing hydrophilic compounds that can be easily disposed of by the animal's metabolism. The new pesticides are systemic, meaning they can be taken up by the plants and animals and distributed through their tissues without accumulating in any particular organ or structure (e.g. fatty tissues). This applies to herbicides as much as to fungicides and insecticides. In addition, hormone-mimicking chemicals and growth regulators specific to arthropods are replacing the traditional neurotoxic insecticides, because most of the latter products are broad-spectrum insecticides that cause numerous fatalities among applicators and wildlife alike [5-7]. And yet, the environmental toxicology of most of these new compounds remains largely unexplored.

What have we learned from the recent history of ecotoxicology? Are we in a better position to assess the ecological impact of new pesticides? Do we understand the pathways that lead to sub-lethal effects in organisms? Have we developed more effective ways of evaluating the toxicity of chemicals? It is regrettable that we are still using methods that consider only fixed times at short periods to evaluate the acute toxicity of chemicals while ignoring the toxic dynamics with time. When would the regulatory authorities establish the much needed time-to-event toxicity protocols as the standard test for ecotoxicity? How can we predict indirect effects on pesticides on communities and ecosystems? These and many other questions pose serious doubts to our ability to interpret and analyse all the toxicological information available to scientists and regulators. We must admit that our current methods for risk assessment of chemicals are deficient and inadequate, so many are the gaps in knowledge that need to be covered. Unless we improve our ways of doing environmental toxicology, human health and environmental protection will be compromised in the future.

This special issue provides a glimpse of the questions that remain to be answered as well as the new directions undertaken to provide answers in this field of research. For a start, Tennekes and SanchezBayo [8] address the toxicology of Neonicotinoids, carcinogens and other compounds with time-dependent toxicity from a toxic dynamic perspective. Based on sound toxicological principles and models, they show empirical evidence that confirm the long-term effects of the novel insecticides on aquatic arthropods and ecosystems. This contrasts with the more familiar toxicology of metals and other compounds that do not have cumulative effects over time. In any case, the toxic dynamic model used to predict the effects of either type of chemical is the same. Its implication for a new approach to risk assessment is sketched.

Sanchez-Bayo [9] reviews the current knowledge status about the toxicity of insecticides to non-target organisms, focusing on the mode of action as the key to understand why some insecticides are more toxic than others to particular groups of organisms. This is a comparative study based on acute toxicity values obtained from several sources. But effects are not restricted to acute toxicity, and there are many other endpoints that need to be considered in ecotoxicology. In this regard, for many years the properties and mode of action of neurotoxic insecticides have been studied on insects (e.g. cockroach, flies). However, the review by $\mathrm{McVey}$ et al. [10] on the astounding features of a humble organism, the nematode Caenorhabditis elegans, opens up a new field in neurotoxicological research. The simple structure of this organism will enable the study of toxicological endpoints, their gene expression and the location of the site of action of insecticides with a detail never seen before. The similarities of its nervous system with that of vertebrates make C. elegans an ideal model organism for neurotoxicity research.

The identification of the specific receptors targeted by the pesticides has taken also a new dimension with the introduction of imaging techniques that reveal the site of action in biological samples. Ortega and Carmona [11] review the recent applications in pesticide toxicology of analytical methods with high detection sensitivity and high spatial resolution such as the ion beam, synchrotron, or mass spectrometry based imaging methods. Such methods enable the determination in

*Corresponding authors: Francisco Sánchez-Bayo, Centre for Ecotoxicology, University of Technology Sydney, Lidcombe NSW 2141, Australia, E-mail: sanchezbayo@mac.com

Richard Ortega, University of Bordeaux, CENBG, UMR 5797, F-33170 Gradignan, France, E-mail: ortega@cenbg.in2p3.fr

Received June 27, 2012; Accepted June 28, 2012; Published June 30, 2012

Citation: Sánchez-Bayo F, Ortega R (2012) Special issue on Toxicology of Pesticides. J Environ Anal Toxicol S4:e001. doi:10.4172/2161-0525S4-e001

Copyright: (C) 2012 Sánchez-Bayo F, et al. This is an open-access article distributed under the terms of the Creative Commons Attribution License, which permits unrestricted use, distribution, and reproduction in any medium, provided the original author and source are credited. 
situ of the distribution of a toxic chemical in the tissues, as well as the speciation of inorganic and organometallic pesticides.

Several clinical disorders in humans have been associated with pesticide usage in agricultural communities, and clinical evidence obtained in recent decades indicates that neurotoxic insecticides are among the substances to blame [12]. Indeed, the variety of sublethal effects that these highly toxic substances cause is only starting to unravel, as Esquivel-Sentíes and Vega explain [13]. Apart from the obvious neurotoxic effects of the insecticides, some metabolites of organophosphorus compounds produce also immunological disturbances by reducing the viability of $\mathrm{T}_{c}$ lymphocytes, which are essential to kill pathogen-infested cells. Thus, the ability of exposed individuals to deal with viral infections and cancerous cells is hampered, not only in humans but in animals as well.

Immunological sublethal effects of the neonicotinoid imidacloprid, one of the most common insecticides used worldwide, in chickens are demonstrated by Kammon and Brar [14]. These authors show the decline in immunoglobulins and lymphocytic depletion in the medulla and cortex in animals treated with this insecticide. This finding is key to understand the recent observations involving infectious diseases and neonicotinoid usage. This weakening effect in chickens, however, can be ameliorated by supplementation of vitamin $\mathrm{E}$ and selenium, which appear to restore the function of the spleen. Further epidemiological studies on neonicotinoids and the honey bee Colony Collapse Disorder should take into account these findings.

In a final contribution to this issue, the controversial teratogenic effects of high doses of glyphosate in frog and chicken embryos are discussed by Fagan and Robinson [15] in relation to other industrybased studies on this matter. The authors question the assessment reports of some government authorities and call for a more transparent risk evaluation to be carried out by independent scientists with no links to industry or government bodies. The underlying hurdle, however, is not so much the biased approached of some industry studies, but rather the misinterpretation of the factual data due to inappropriate knowledge about the sublethal effects that pesticides exert on organisms.

While this selection of articles is small, we hope the topics covered may prompt further research on the toxicology of pesticides from new perspectives. Only thus we will be able to tackle the above questions in a more appropriate way.

\section{References}

1. Carson R (1962) Silent Spring, Houghton-Mifflin, Boston, MA

2. Sánchez-Bayo F, van den Brink PJ, Mann RM (2011) Ecological Impacts of Toxic Chemicals. Bentham Science Publishers Ltd. Online, 281.

3. Lockie JD, Ratcliffe DA (1964) Insecticides and Scottish golden eagles. British Birds 57: 89-101.

4. Dunlap TR (1981) DDT, Scientists, Citizens and Public Policy, Princeton University Press, Princeton, NJ.

5. Garry VF, Harkins ME, Erickson LL, Long-Simpson LK, Holland SE, et al. (2002) Birth defects, season of conception, and sex of children born to pesticide applicators living in the Red River Valley of Minnesota, USA. Environ Health Perspect 110: 441-449.

6. Mineau $P$, Whiteside $M(2006)$ Lethal risk to birds from insecticide use in the United States - A spatial and temporal analysis. Environ Toxicol Chem 25: 1214-1222.

7. Konradsen F, van der Hoek W, Cole DC, Hutchinson G, Daisley H, et al. (2003) Reducing acute poisoning in developing countries--options for restricting the availability of pesticides. Toxicology 192: 249-261.

8. Tennekes HA, Sánchez-Bayo F (2012) Time-dependent toxicity of neonicotinoids and other toxicants: implications for a new approach to risk assessment. J Environ Anal Toxicol S4-001.

9. Sánchez-Bayo $F(2012)$ Insecticides mode of action in relation to their toxicity to non-target organisms. J Environ Anal Toxicol S4: S4-002.

10. McVey KA, Mink JA, Snapp IB, Timberlake WS, Todt CE, et al. (2012) Caenorhabditis elegans: An emerging model system for pesticide neurotoxicity. J Environ Anal Toxicol S4: S4-003.

11. Ortega R, Carmona A (2012) High spatial resolution chemical imaging of inorganic and organometallic pesticides. J Environ Anal Toxicol S4: S4-005.

12. Parrón T, Requena M, Hernández AF, Alarcón R (2011) Association between environmental exposure to pesticides and neurodegenerative diseases. Toxicol Appl Pharmacol 256: 379-385.

13. Esquivel-Senties MS, Vega L (2012) Organophosphorous pesticides metabolite reduces human $\mathrm{T}$ CD8 homeostasis and proliferation by inducing cellular death. J Environ Anal Toxicol S4: S4-004.

14. Kammon AM, Brar RS (2012) Ameliorating effects of vitamin $E$ and selenium on immunological alterations induced by imidacloprid chronic toxicity in chickens. J Environ Anal Toxicol S4: S4-007

15. Fagan JB, Robinson CJ (2012) Teratogenic effects of glyphosate-based herbicides and political and scientific controversy. J Environ Anal Toxicol S4: S4-006.
This article was originally published in a special issue, Toxicology of Pesticides handled by Editor(s). Dr. Francisco Sanchez Bayo, Australia; Dr. Richard ORTEGA, France 